\title{
La collection Ad usum Delphini, vol. II, sous la direction de Martine Furno
}

\section{Daniela Dalla Valle}

\section{Q OpenEdition \\ 1 Journals}

Edizione digitale

URL: http://journals.openedition.org/studifrancesi/27552

ISSN: 2421-5856

\section{Editore}

Rosenberg \& Sellier

\section{Edizione cartacea}

Data di pubblicazione: 31 décembre 2006

Paginazione: 598-599

ISSN: 0039-2944

\section{Notizia bibliografica digitale}

Daniela Dalla Valle, "La collection Ad usum Delphini, vol. II, sous la direction de Martine Furno », Studi Francesi [Online], 150 (L | III) | 2006, online dal 30 novembre 2015, consultato il 08 novembre 2020. URL : http://journals.openedition.org/studifrancesi/27552

Questo documento è stato generato automaticamente il 8 novembre 2020.

\section{(c) (1)}

Studi Francesi è distribuita con Licenza Creative Commons Attribuzione - Non commerciale - Non opere derivate 4.0 Internazionale. 


\title{
La collection Ad usum Delphini, vol. II, sous la direction de Martine Furno
}

\author{
Daniela Dalla Valle
}

\section{NOTIZIA}

La collection Ad usum Delphini, vol. II, sous la direction de Martine FURNo, Grenoble, ELLUG, Université Stendhal, 2005, pp. 532.

1 Dopo il primo volume - La collection ad usum Delphini. L'Antiquité au miroir du Grand Siècle, curato da Catherine Volpilhac-Auger, consacrato alla collezione nel suo insieme, alla sua elaborazione e ai suoi aspetti bibliofili e pedagogici, pubblicato nella stessa collezione nel 2000 - esce ora il secondo e ultimo volume, dedicato alle ricerche svolte dalla ricca équipe che ha collaborato al lavoro, sugli autori latini pubblicati nella collezione. Si tratta di 39 autori, la cui notice comprende - regolarmente un'indicazione dell'edizione Ad usum Delphini, elementi biografici sul commentatore, la descrizione del posto dell'edizione Ad usum Delphini nella storia del testo latino, la descrizione completa dell'edizione studiata, uno studio analitico e un bilancio conclusivo sull'edizione stessa. Gli autori vanno da Sallustio (uscito nel 1674) ad Ausonio (l'unico uscito nel XVIII secolo, nel 1729). Fra gli autori pubblicati in questa collezione e analizzati, ricordiamo Terenzio, Virgilio, Cesare, Tito Livio, Tacito, Cicerone, Catullo, Ovidio, Orazio, ma anche Apuleio, Giustino, Boezio.

2 Il volume apre un'interessante prospettiva su un settore della cultura nel tardo Seicento. 